\title{
Fertility Preservation in Patients With Breast Cancer: Necessity, Methods, and Safety
}

\author{
Adrienne G. Waks, MD, a, and Ann H. Partridge, MD, $\mathrm{MPH}^{\mathrm{a}, \mathrm{b}}$
}

\begin{abstract}
As treatment paradigms improve and young women live longer after a breast cancer diagnosis, there is an increasing need to define the fertility-related problems that premenopausal women with breast cancer face, and, more importantly, to find solutions. This article discusses what is known regarding fertility risks associated with standard breast cancer treatment regimens and limitations of that information. We outline established and emerging techniques for fertility preservation, including recent developments surrounding the controversial utility of gonadotropin-releasing hormone agonists through chemotherapy, and review available data on the safety of pregnancy in breast cancer survivors. We highlight opportunities for further investigation, and contextualize fertilityrelated concerns in the modern treatment landscape. Above all, we stress the importance of this topic in a patient-centered approach to breast cancer care for young women.
\end{abstract}

J Natl Compr Canc Netw 2016;14(3):355-363

\section{NCCN: Continuing Education}

\section{Accreditation Statement}

This activity has been designed to meet the educational needs of physicians and nurses involved in the management of patients with cancer. There is no fee for this article. No commercial support was received for this article. The National Comprehensive Cancer Network (NCCN) is accredited by the ACCME to provide continuing medical education for physicians.

NCCN designates this journal-based CME activity for a maximum of 1.0 AMA PRA Category 1 Credit $^{\mathrm{TM}}$. Physicians should claim only the credit commensurate with the extent of their participation in the activity.

NCCN is accredited as a provider of continuing nursing education by the American Nurses Credentialing Center's Commission on Accreditation.

NCCN designates the education activity for a maximum of 1.0 contact hour. Accreditation as a provider refers to recognition of educational activities only; accredited status does not imply endorsement by NCCN or ANCC of any commercial products discussed/

From the aDepartment of Medical Oncology, Dana-Farber Cancer Institute, and ' ${ }^{\circ}$ arvard Medical School, Boston, Massachusetts.

Submitted November 4, 2015; accepted for publication January 2, 2016.

The authors have disclosed that they have no financial interests, arrangements, affiliations, or commercial interests with the manufacturers of any products discussed in this article or their competitors.

Correspondence: Ann H. Partridge, MD, MPH, Dana-Farber Cancer Institute, 450 Brookline Avenue, Boston, MA 02215.

E-mail: ann_partridge@dfci.harvard.edu

\section{EDITOR}

Kerrin M. Green, MA, Assistant Managing Editor, JNCCN—Journal of the National Comprehensive Cancer Network displayed in conjunction with the educational activity. Kristina M. Gregory, RN, MSN, OCN, is our nurse planner for this educational activity.

All clinicians completing this activity will be issued a certificate of participation. To participate in this journal CE activity: 1) review the learning objectives and author disclosures; 2 ) study the education content; 3) take the posttest with a $66 \%$ minimum passing score and complete the evaluation at http://education.nccn.org/ node/78105; and 4) view/print certificate.

Release date: March 10, 2016; Expiration date: March 10, 2017

\section{Learning Objectives}

Upon completion of this activity, participants will be able to:

- Assess and address fertility-related concerns as part of routine care in women of child-bearing age with breast cancer

- Outline both the established and emerging techniques for fertility preservation

- Review the barriers in fertility preservation and available data on the safety of pregnancy in breast cancer survivors

Ms. Green has disclosed that she has no relevant financial relationships.

\section{CE AUTHORS}

Deborah J. Moonan, RN, BSN, Director, Continuing Education, has disclosed that she has no relevant financial relationships.

Ann Gianola, MA, Manager, Continuing Education Accreditation \& Program Operations, has disclosed that she has no relevant financial relationships.

Kristina M. Gregory, RN, MSN, OCN, Vice President, Clinical Information Operations, has disclosed that she has no relevant financial relationships. Rashmi Kumar, PhD, Senior Manager, Clinical Content, has disclosed that she has no relevant financial relationships. 
Waks and Partridge

Fertility preservation is a central element of survivorship for many of the more than 25,000 reproductive-aged women diagnosed with breast cancer each year. ${ }^{1}$ With approximately $15 \%$ of diagnoses occurring in women of reproductive age, breast cancer is the most common malignancy diagnosed in this age subset. ${ }^{2,3}$ Given the increasing population of young women, the modern trend for women in our society to delay childbearing until later in life, ${ }^{2,4}$ and ongoing improvements in breast cancer survival, the population of women who desire pregnancy after a breast cancer diagnosis is increasing. However, data indicate that pregnancy rates among cancer survivors are significantly lower than in matched controls. This gap is particularly marked in breast cancer survivors: in a registry-based study from Norway, the hazard ratio (HR) for pregnancy in female breast cancer survivors, compared with healthy controls, was 0.33 (95\% CI, 0.27-0.39). By contrast, the pregnancy HR for all female cancer survivors compared with healthy controls was 0.61 (95\% CI, 0.58-0.64), and the chance of pregnancy in a female survivor of thyroid cancer or melanoma was equivalent to that in healthy controls. ${ }^{5}$ Therefore, now more than ever, breast cancer clinicians must assess and address fertility-related concerns as part of routine care in young women with breast cancer.

However, fertility risks and preservation options are presently underdiscussed by the medical oncology community. ${ }^{6}$ In one study of women diagnosed with localized breast cancer at 40 years of age or younger, only $68 \%$ reported having discussed fertility issues with their clinical team before starting therapy, ${ }^{7}$ and in a physician survey in the United States, fewer than half of oncology providers always or often referred patients with fertility-related questions to a fertility specialist. ${ }^{8}$ Even when issues are addressed, there is a dearth of information to inform fertility concerns and decision-making. Although the fertility implications of breast cancer diagnosis and treatment carry significant weight for most young women with breast cancer, ${ }^{7}$ studies of fertility outcomes are currently limited, decision-making around pregnancy and fertility preservation remains highly individualized, and large studies in this area have been difficult to accomplish, even as the relevant population expands. Nonetheless, recent data and ongoing research continue to improve our understanding of the fertility-related risks and the pros and cons of interventions to preserve fertility for young breast cancer survivors.

\section{The Impact of Breast Cancer Treatment on Fertility}

The risk of infertility related to breast cancer treatment is a difficult topic to study for a variety of reasons. First, few studies have focused on and collected pertinent outcomes, such as return of menses, successful pregnancy, and timing of permanent menopause after systemic therapy. ${ }^{9}$ Second, it is difficult to determine the right metric for fertility. Although it is easiest to assess for the presence or absence of menses, data in the postchemotherapy population demonstrate that ovarian reserve may be diminished despite the resumption of regular menses..$^{10,11}$ For feasibility purposes, menses are equated with fertility in much of the breast cancer fertility literature, necessitating the use of this equivalence throughout this review; however, it should be noted that menstruation does not necessarily connote fertility. Lastly, there appears to be substantial heterogeneity in outcomes between patients, and only limited research has identified important patient-specific determinants beyond age. In one retrospective study of premenopausal patients with breast cancer, the odds ratio of developing chemotherapy-related amenorrhea (CRA) was 10.1 and 39.5 in patients aged 35 to 39 years and 40 to 44 years, respectively, compared with a reference group of patients younger than 35 years old. ${ }^{12}$ Given that the risk of CRA increases by an order of magnitude over just a 5- to 10-year interval, considering average CRA rates for all premenopausal women is of limited value for an individual patient; age-stratified data and discovery of biomarkers predictive of fertility after treatment are needed and are the focus of ongoing research efforts.

Despite these limitations, a general understanding and estimation of a woman's infertility risk with a specific treatment regimen are necessary components of effective fertility preservation counseling. Table 1 summarizes data on rates of persistent CRA after different chemotherapy regimens, with a focus on modern regimens and on analyses that separate patients by age group. CRA rates in patients older than 50 years are not included in the table, because rates approach $100 \%$ regardless of chemotherapy regimen as women approach the age of natural menopause. ${ }^{12}$ 
Fertility in Breast Cancer

\begin{tabular}{|c|c|c|c|c|}
\hline Chemotherapy & Age $\leq 30 y$ & Age $31-35$ y & Age $36-40$ y & Age $>40 y$ \\
\hline $\mathrm{CMF}^{50, \mathrm{a}}$ & $19 \%$ & $30 \%-40 \%$ & & $80 \%-95 \%$ \\
\hline $\mathrm{CMF}^{14, a, b}$ & $40 \%$ & & & $76 \%$ \\
\hline $\mathrm{CMF}^{14, a}$ & $4 \%$ & & $50 \%$ & $86 \%-100 \%$ \\
\hline $\mathrm{CEF}^{51}$ & $47 \%$ & & & $80 \%-100 \%$ \\
\hline A-containing ${ }^{14}$ & $0 \%$ & $33 \%$ & & $96 \%-100 \%$ \\
\hline$A C^{12}$ & $13.9 \%$ & & $68.2 \%$ & \\
\hline$A C-T^{12}$ & $9 \%-13 \%$ & & $65 \%-73 \%$ & \\
\hline $\mathrm{AC}-\mathrm{T}+/-\mathrm{H}^{15}$ & $9 \%-20 \%$ & $19 \%-47 \%$ & $21 \%-61 \%$ & No data \\
\hline AC-TH ${ }^{12}$ & $0 \%-14 \%$ & & $56 \%-67 \%$ & \\
\hline $\mathrm{TH}^{18}$ & $28 \%$ & & & \\
\hline
\end{tabular}

Abbreviations: A, doxorubicin; AC, doxorubicin/cyclophosphamide; CEF, cyclophosphamide/epirubicin/5-fluorouracil; CMF, cyclophosphamide/ methotrexate/5-fluorouracil; $\mathrm{H}$, trastuzumab; T, paclitaxel; $\mathrm{TH}$, paclitaxel/trastuzumab.

aEither these data reflect combinations of cyclophosphamide administration route (intravenous vs oral) and duration, or those specifics are not available.

${ }^{\mathrm{b}}$ All patients treated with CMF for at least 3 months.

A few general principles for predicting ovarian toxicity of breast cancer chemotherapy should be underscored. The risk of CRA directly correlates with cyclophosphamide dose, because alkylating agents are particularly gonadotoxic. ${ }^{11,13}$ Hence, cyclophosphamide/methotrexate/5-fluorouracil (CMF) causes significantly higher rates of CRA than doxorubicin/ cyclophosphamide (AC) (69\% vs 34\%, respectively, in one nonrandomized study in which CMF was administered as $100 \mathrm{mg} / \mathrm{m}^{2}$ orally on days $1-14$ of a 28 -day cycle for 6 cycles, resulting in $8,400 \mathrm{mg} / \mathrm{m}^{2}$ total cyclophosphamide), in large part because standard CMF administration entails much higher cyclophosphamide dosing than the standard 4 cycles of AC. ${ }^{14}$ It should be noted that cyclophosphamide as a component of CMF can be administered via different dosing routes (intravenous vs oral), schedules, and durations, and although it is clear that greater cumulative dose confers an increased risk of CRA, the impact of administration route and dose intensity/duration on CRA is not known. ${ }^{14}$ Although some data suggest that adding a taxane to a standard AC regimen does not appear to add a significant fertilityassociated risk compared with $\mathrm{AC}$ alone, ${ }^{12,15}$ other data indicate that some additive taxane-associated risk does exist. ${ }^{16}$ The gonadotoxic effect of docetaxel is also unclear; one recent analysis suggests that docetaxel/cyclophosphamide (TC) is no worse than $\mathrm{AC}$ in terms of CRA rates, ${ }^{15}$ but this result is based on a single small cohort that was not powered for this comparison, and must be interpreted with caution. Further investigation of docetaxel-based regimens is warranted. Gathering data on the clinical gonadotoxicity of platinum agents should also be a priority, given recent evidence that platinum compounds are particularly effective in BRCA1/2-mutated patients. ${ }^{17}$

Of relevance to HER2-positive patients, available data suggest no significant additive impact on amenorrhea from 1 year of trastuzumab therapy, ${ }^{12}$ and the CRA rate associated with paclitaxel/trastuzumab (TH) for women with small HER2-positive tumors ( $28 \%$ across all age groups) is likely driven by the paclitaxel and may not be significantly higher than natural menopausal rates in a similarly aged population, ${ }^{18}$ although these findings require further validation in additional cohorts. In women treated for hormone receptor-positive early-stage breast cancer, multiple studies demonstrate an association between tamoxifen use and persistence of postchemotherapy amenorrhea. ${ }^{12,19,20}$ Rather than representing a gonadotoxic effect of tamoxifen, this likely reflects the known association of tamoxifen with menstrual irregularities, in addition to the natural age-related loss in ovarian reserve that occurs over a standard 5- to 10-year course of tamoxifen.

Shaping expectations around the timing of loss and resumption of menses may also be of practical use in counseling patients. In one prospective cohort of premenopausal patients with breast cancer with a 
Waks and Partridge

median age of 39.5 years, $88 \%$ experienced at least 3 months of amenorrhea while undergoing chemotherapy, and there was no discernible difference between the patients who lost versus maintained menstruation while on chemotherapy. ${ }^{21}$ Among patients who resume menstruation, this occurs within 6 months of chemotherapy completion in $62 \%$, within 6 to 12 months of completion in an additional $31 \%$, and beyond 12 months in only $7 \%$ of patients. ${ }^{12}$ Based on these data, although most women will become amenorrheic while on chemotherapy, most of those who will resume menstruation do so within 12 months. In contrast, a woman who remains amenorrheic for more than a year postchemotherapy has a very low chance of regaining normal menstrual function.

Given the substantial interindividual variability in the risk of CRA, additional patient-specific parameters to predict which patients are at highest risk are needed. As depicted in Table 1, patient age and treatment received dominate risk estimates. Recently, pretreatment levels of antimüllerian hormone $(\mathrm{AMH})$ have consistently appeared to predict chances of postchemotherapy recovery of ovarian reserve and menstruation. ${ }^{21-23}$ In one multivariable model, baseline body mass index (BMI) in the overweight or obese range (compared with the normal range) also predicted menstrual resumption, in addition to age and AMH levels, although data regarding BMI have been inconsistent. ${ }^{12,21}$ Ongoing and future research in this area is clearly needed.

\section{Fertility Preservation Options for Patients With Breast Cancer}

A number of strategies are available or are in development to maximize the potential for future childbearing in patients with breast cancer who desire to preserve fertility. An overview of the options, including their relative advantages and disadvantages and the status of their clinical availability, is provided in Table 2. In brief, the best established method is embryo cryopreservation, which involves a protocol of controlled ovarian stimulation using exogenous hormones to achieve ovarian follicle maturation, followed by in vitro fertilization (IVF) and embryo freezing. ${ }^{3}$ Oocyte cryopreservation, which was adopted as a standard treatment for infertility in 2012 by the American Society for Reproductive Medicine when success rates were improved, ${ }^{24}$ is similar to em- bryo cryopreservation except that oocytes are frozen before fertilization.

One of the concerns associated with both of these methods is the need to delay cancer treatment. Part of the need for this delay, which is usually only a few weeks, arises from the standard practice of waiting to begin ovarian stimulation until the follicular phase of the menstrual cycle. To address this, alternative protocols for timing ovarian stimulation have been developed. Recent data suggest that the number of aspirated oocytes and the oocyte fertilization rate obtained after stimulation starting in the standard follicular phase versus the nonstandard luteal phase of the cycle are not significantly different, indicating that both phases may be viable options. ${ }^{25}$

The second major issue associated with standard ovarian stimulation methods is the use of exogenous hormones to produce grossly supraphysiologic (approximately 10 times normal) estrogen levels, ${ }^{3,26}$ a concern in patients with hormonesensitive malignancy. Although standard stimulation protocols require on average 10 to 11 days of gonadotropins, the omission of stimulation has been explored. Unfortunately, such natural-cycle IVF, which involves aspiration of a woman's existing ovarian follicles without performing controlled ovarian stimulation, provides a relatively low yield, producing one embryo in only $60 \%$ of cycles. ${ }^{27,28}$ Use of alternative, less strongly estrogenic agents for ovarian stimulation appears more promising. In a prospective, controlled, nonrandomized study of 60 women with breast cancer before chemotherapy, tamoxifen plus the gonadotropin folliclestimulating hormone (FSH) and letrozole plus FSH both produced a higher embryo yield than tamoxifen alone. ${ }^{26}$ Tamoxifen alone, in turn, works better than natural-cycle IVF. ${ }^{28}$ Two prospective studies, containing a total of 275 premenopausal patients with breast cancer undergoing IVF before chemotherapy, demonstrate that these alternative ovarian stimulation protocols do not appear to be associated with any increased risk of breast cancer recurrence. $^{26,29}$ Importantly, pregnancy outcomes after ovarian stimulation with letrozole and gonadotropins in premenopausal, prechemotherapy patients with breast cancer are on par with those of the noncancer population, with a $51.5 \%$ fertility preservation rate among 33 women who attempted pregnancy using cryopreserved embryos. ${ }^{2}$ 
Fertility in Breast Cancer

Table 2. Potential Fertility Preservation Options for Premenopausal Patients With Breast Cancer

\begin{tabular}{|c|c|c|c|c|}
\hline & Overview & $\begin{array}{l}\text { Status of } \\
\text { Clinical } \\
\text { Adoption }\end{array}$ & Advantages & Disadvantages \\
\hline \multirow[t]{5}{*}{$\begin{array}{l}\text { Embryo } \\
\text { cryopreservation }\end{array}$} & $\begin{array}{l}\text { Ovarian stimulation starting } \\
\text { at menses onset }{ }^{6}\end{array}$ & \multirow[t]{5}{*}{ Standard ${ }^{24}$} & \multirow[t]{5}{*}{$\begin{array}{l}\text { Longest established of } \\
\text { all available methods }{ }^{3}\end{array}$} & \multirow{2}{*}{$\begin{array}{l}\text { Requires } \\
\text { hormonal } \\
\text { stimulation }\end{array}$} \\
\hline & Egg retrieval & & & \\
\hline & In vitro fertilization & & & \multirow{2}{*}{$\begin{array}{l}\text { Requires 2- to } \\
6 \text {-wk treatment } \\
\text { delay }\end{array}$} \\
\hline & Cryopreservation ${ }^{27}$ & & & \\
\hline & & & & $\begin{array}{l}\text { Requires male } \\
\text { partner }^{6}\end{array}$ \\
\hline \multirow[t]{3}{*}{$\begin{array}{l}\text { Mature oocyte } \\
\text { cryopreservation }\end{array}$} & $\begin{array}{l}\text { Ovarian stimulation starting } \\
\text { at menses onset }{ }^{6}\end{array}$ & \multirow[t]{3}{*}{ Standard ${ }^{24}$} & \multirow[t]{3}{*}{$\begin{array}{l}\text { No male partner } \\
\text { needed }^{3}\end{array}$} & \multirow{2}{*}{$\begin{array}{l}\text { Requires } \\
\text { hormonal } \\
\text { stimulation }\end{array}$} \\
\hline & Egg retrieval & & & \\
\hline & Cryopreservation $^{27}$ & & & $\begin{array}{l}\text { Requires } 2 \text { - to } \\
6 \text {-wk treatment } \\
\text { delay }^{6}\end{array}$ \\
\hline \multirow{4}{*}{$\begin{array}{l}\text { Ovarian tissue } \\
\text { cryopreservation } \\
\text { for } \\
\text { reimplantation }\end{array}$} & Oophorectomy & \multirow{4}{*}{$\begin{array}{l}\text { Investigational, } \\
\text { potentially } \\
\text { promising }^{24}\end{array}$} & \multirow{3}{*}{$\begin{array}{l}\text { No hormonal } \\
\text { stimulation needed } \\
\text { Less treatment delay } \\
\text { than standard methods }\end{array}$} & \multirow{4}{*}{$\begin{array}{l}\text { Potential for } \\
\text { reintroduction of } \\
\text { cancer cells with } \\
\text { ovarian tissue }^{24}\end{array}$} \\
\hline & Ovarian tissue & & & \\
\hline & Autologous reimplantation & & & \\
\hline & of ovarian tissue ${ }^{27}$ & & $\begin{array}{l}\text { No male partner } \\
\text { needed }^{27}\end{array}$ & \\
\hline \multirow{7}{*}{$\begin{array}{l}\text { Ovarian tissue } \\
\text { cryopreservation } \\
\text { for in vitro } \\
\text { follicle } \\
\text { maturation }\end{array}$} & Oophorectomy & \multirow{7}{*}{$\begin{array}{l}\text { Investigational, } \\
\text { potentially } \\
\text { promising }^{27}\end{array}$} & \multirow{2}{*}{$\begin{array}{l}\text { No hormonal } \\
\text { stimulation needed }\end{array}$} & \\
\hline & Ovarian tissue & & & \\
\hline & cryopreservation & & \multirow{2}{*}{$\begin{array}{l}\text { Less treatment delay } \\
\text { than standard methods }\end{array}$} & \\
\hline & Aspirate immature oocyte, & & & \\
\hline & mature in vitro & & \multirow{3}{*}{$\begin{array}{l}\text { No male partner } \\
\text { needed }^{27}\end{array}$} & \\
\hline & In vitro fertilization & & & \\
\hline & Uterine transfer ${ }^{27}$ & & & \\
\hline \multirow[t]{3}{*}{$\begin{array}{l}\text { Natural cycle in } \\
\text { vitro fertilization }\end{array}$} & $\begin{array}{l}\text { Ovarian follicle aspirated } \\
\text { during natural menstrual } \\
\text { cycle }\end{array}$ & \multirow[t]{3}{*}{$\begin{array}{l}\text { Investigational, } \\
\text { limited success }{ }^{28}\end{array}$} & \multirow[t]{3}{*}{$\begin{array}{l}\text { No hormonal } \\
\text { stimulation needed }{ }^{28}\end{array}$} & \multirow[t]{3}{*}{ Low success rate ra $^{26}$} \\
\hline & In vitro fertilization & & & \\
\hline & Cryopreservation & & & \\
\hline \multirow[t]{2}{*}{ GnRH agonist } & \multirow{2}{*}{$\begin{array}{l}\text { Administer every } 4 \mathrm{wk} \\
\text { starting } 1 \mathrm{wk} \text { before } \\
\text { chemotherapy } \\
\text { 20,33 }\end{array}$} & \multirow{2}{*}{$\begin{array}{l}\text { Provider- } \\
\text { dependent, } \\
\text { controversial } \\
\text { (see text) }\end{array}$} & \multirow[t]{2}{*}{ Noninvasive } & $\begin{array}{l}\text { Mixed efficacy } \\
\text { data (see text) }\end{array}$ \\
\hline & & & & $\begin{array}{l}\text { Slight increase } \\
\text { in low-grade } \\
\text { toxicities }^{33}\end{array}$ \\
\hline
\end{tabular}

Abbreviation: $\mathrm{GnRH}$, gonadotropin-releasing hormone.

Additional fertility-preserving methods are in development, including cryopreservation of ovarian tissue itself. This process involves surgical oophorectomy and cryopreservation of ovarian cortical strips before chemotherapy. Subsequently, the ovarian tissue is thawed and transplanted back into the host in an autologous fashion. ${ }^{27}$ The first report of a successful pregnancy resulting from this method, documented in a young woman who became infertile after receiving high-dose chemotherapy for non-Hodgkin's lymphoma, was published in $2005 . .^{30}$ As of 2015 , at least 42 live births had been achieved via autotransplantation of ovarian tissue. ${ }^{31}$ Aside from its limited success rate to date, the main risk of this technique is the potential to transplant malignant cells back into the body along with ovarian tissue, although this has never been reported, and multiple histologic and microscopic screening measures to minimize this risk are available. ${ }^{24,31}$ In vitro follicle maturation is a more recent extension of ovarian tissue cryopreserva- 
Waks and Partridge

tion, in which immature follicles are aspirated from stored ovarian tissue, matured in vitro, then fertilized and transferred to the uterus. ${ }^{27}$ The first successful pregnancy achieved by this method was reported in $2014 .{ }^{32}$ Although promising, both of these ovarian cryopreservation-based techniques remain investigational and are not generally available to patients with breast cancer outside of a clinical trial. ${ }^{24}$

A final potential fertility preservation strategy, and a topic of much debate, is the use of gonadotropin-releasing hormone $(\mathrm{GnRH})$ agonists concurrent with chemotherapy. Use of $\mathrm{GnRH}$ agonists has been posited to improve the chances of ovarian recovery postchemotherapy through a variety of mechanisms, including decreasing ovarian and uterine perfusion, increasing antiapoptotic mechanisms within the ovary, and protecting germline stem cells. ${ }^{20}$ Two large breast cancer-specific randomized controlled trials of the GnRH agonists triptorelin and goserelin both demonstrated a significantly lower rate of postchemotherapy ovarian failure in patients receiving, a GnRH agonist plus chemotherapy versus chemotherapy alone: $8 \%$ versus $22 \%$, respectively, in the Prevention of Early Menopause Study (POEMS) $(P=.02),{ }^{33}$ and $8.9 \%$ versus $25.9 \%$, respectively, in the PROMISE trial (Prevention of Menopause Induced by Chemotherapy: A Study in Early Breast Cancer Patients) $(P<.001) .{ }^{20}$ Additionally, in POEMS, significantly more pregnancies were seen in women who received goserelin $(21 \%)$ than in those who did not $(11 \%$; $P$ value for comparison $=.03) .{ }^{33}$ Of note, all women enrolled in POEMS had hormone receptor-negative breast cancer, whereas approximately $80 \%$ of women in PROMISE had hormone receptor-positive breast cancer. In POEMS, ovarian failure was defined at 2 years as lack of menses in the preceding 6 months and FSH levels in the postmenopausal range; in PROMISE, ovarian failure was defined as lack of menses and FSH levels in the postmenopausal range for 1 year after chemotherapy. ${ }^{20,33}$

Although increasing data support the use of GnRH agonists for ovarian protection, it is important to note that the overall body of evidence remains inconsistent. Many other randomized trials addressing this question in both hormone receptorpositive and hormone receptor-negative breast cancer have been performed, some with negative results. ${ }^{34,35}$ A number of large meta-analyses have also reached disparate conclusions, some supporting and some rejecting the benefit of $\mathrm{GnRH}$ agonists as a fertility preservation approach. ${ }^{36-38}$ A patient-level meta-analysis is underway using data from all of the available randomized controlled trials, and the hope is that results will inform future guidelines in this regard. Currently, given the lack of safety concerns, it is reasonable to consider using this strategy in women who wish to add this to other options or for whom other options are not feasible.

Understanding the risks associated with adding GnRH agonists to chemotherapy is essential for counseling patients about this strategy. Grade 3 adverse events do not increase significantly; however, rates of grade 2 and higher toxicities are increased with the addition of a GnRH agonist (48\% with goserelin plus chemotherapy vs $24 \%$ with chemotherapy alone), with the most marked differences being increased incidence of hot flashes and headaches in the goserelin group. ${ }^{33}$

There is also the theoretical concern that using a GnRH agonist (an antiestrogen agent) during chemotherapy could decrease chemotherapy efficacy in hormone receptor-positive breast cancer. This concern arises from previous evidence in postmenopausal women with hormone-responsive breast cancer suggesting that concurrent tamoxifen (also an antiestrogen agent) during chemotherapy was associated with an increased risk of disease recurrence compared with tamoxifen after chemotherapy. ${ }^{39}$ However, tamoxifen and a GnRH agonists have entirely different antiestrogen mechanisms, and no evidence shows that GnRH agonists compromise the benefits of chemotherapy. ${ }^{33}$ If use of $\mathrm{GnRH}$ agonists for fertility preservation is widely adopted, then further investigation of the safety of this approach in hormone receptor-positive patients may be worthwhile in order to mitigate this concern. Data sets in which to pose this question already exist: premenopausal women with hormone receptor-positive breast cancer on the Suppression of Ovarian Function Trial (SOFT) were treated with ovarian suppression starting after administration of adjuvant chemotherapy, whereas similar women on the Tamoxifen and Exemestane Trial (TEXT) were treated with ovarian suppression starting during administration of adjuvant chemotherapy. ${ }^{40,41}$ A comparison of these 2 patient groups would potentially help to address the issue of whether ovarian suppression with $\mathrm{GnRH}$ agonist during (as opposed to after) chemotherapy has any detrimental impact on breast cancer outcomes. 
Fertility in Breast Cancer

\section{Barriers to Use of Fertility Preservation}

Limited data suggest that only a minority of premenopausal patients with breast cancer use fertilitypreserving techniques (10\% in one cohort) ${ }^{7}$ and of those who choose to freeze embryos or oocytes, a further minority report using them to attempt subsequent pregnancy. In a cohort of women who underwent embryo cryopreservation before breast cancer chemotherapy, approximately 25\% (33 of 131 women) returned to use the embryos, at a median of 5.25 years after cryopreservation ${ }^{2}$ (it is unknown to what extent this reflects successful pregnancies achieved without reliance on banked embryos).

A variety of factors may contribute to the surprisingly low use of fertility-preserving techniques available for patients with breast cancer. As discussed earlier, a lack of patient awareness due to inadequate discussion of treatment-related fertility risks ${ }^{6-8}$ likely plays a role. Psychosocial concerns are also relevant; in a recent survey-based study from the Netherlands examining women's decision-making regarding fertility preservation before gonadotoxic therapy $(58 \%$ of women in this study had breast cancer), the most important determinants of using fertility preservation methods were the wish to conceive and the presence of a stable partner. Conversely, the most important correlate of foregoing fertility preservation was the expected burden of the process itself. ${ }^{42}$ Cost is an important consideration for many patients, because there can be a significant financial burden associated with embryo/oocyte cryopreservation, and insurance coverage is not required. ${ }^{9}$ Wealthier patients with breast cancer are more likely to undergo fertility-preserving treatment, ${ }^{43}$ and in one nonbreast cancer study of American young adults with cancer, $19 \%$ of women cited finances as a reason to forego fertility preservation. ${ }^{44}$ Lastly, health-related concerns, including fear of future cancer recurrence or treatment-related complications, ${ }^{5}$ anxiety about treatment delay, ${ }^{44}$ and fear about the safety of future pregnancy, all may heighten apprehension about fertility preservation at the time of diagnosis.

\section{Safety of Pregnancy After Breast Cancer}

An important corollary to the question of whether pregnancy can be achieved after breast cancer is whether pregnancy after breast cancer is safe. Because most breast tumors are driven by estrogen signaling, there has been understandable concern about the impact of pregnancy on recurrence risk in breast cancer survivors. However, retrospective multivariable analysis of a large population-based data set and meta-analysis of multiple smaller studies have demonstrated that pregnancy after breast cancer confers no increased risk of adverse outcomes. ${ }^{45,46}$ In fact, if anything, pregnancy after breast cancer is associated with improved survival, an observation that may be attributable at least in part to the "healthy mother effect," the phenomenon that survivors who pursue pregnancy are likely healthier than their counterparts. ${ }^{47}$

Extending these findings, Azim et al ${ }^{48}$ recently performed a multicenter retrospective cohort study to examine breast cancer outcomes postpregnancy according to estrogen receptor status. They found no significant difference in disease-free survival for estrogen receptor-positive (HR for pregnant vs nonpregnant, $0.91 ; 95 \% \mathrm{CI}, 0.67-1.24)$ or estrogen receptor-negative patients (HR for pregnant vs nonpregnant, 0.75; 95\% CI, 0.51-1.08). A small, retrospective cohort study of women who became pregnant after breast cancer has likewise shown that there is no significant detrimental effect of using assisted reproductive technology on breast cancer outcomes. ${ }^{49}$

The POSITIVE trial (Pregnancy Outcome and Safety of Interrupting Therapy for Women with Endocrine Responsive Breast Cancer; ClinicalTrials.gov identifier: NCT02308085) is a currently enrolling single-arm study that will prospectively evaluate the safety of interrupting hormonal therapy to attempt pregnancy for women with hormone receptor-positive breast cancer, including disease, reproductive, and psychosocial outcomes. These data will help address several outstanding questions in this area.

\section{Conclusions}

The medical community is increasingly embracing a care approach focused on maximizing outcomes that matter to patients. For many young women with breast cancer, the prospect of fertility loss is of central importance to their treatment experience, and warrants increased attention. Overcoming the current barriers to fertility preservation in patients with breast cancer requires a multifaceted approach, but this goal is both feasible and worthwhile. The lack of good data and the emotion-laden burden of the topic make it difficult to discuss, but the literature is growing steadily. The multidisciplinary connections necessary to facilitate timely referrals and care are 
Waks and Partridge

a challenge, but must be made. Insurance coverage prohibits some patients with cancer from accessing the fertility services that they need, but this is expanding. ${ }^{9}$ Lastly, as emerging data like those from the SOFT and TEXT trials teach us more about the efficacy of combined hormonal blockade, ${ }^{40,41}$ we must be increasingly discriminating about which patients should receive chemotherapy. Thankfully, most young patients with breast cancer will do very well. Thus, the burden is on us to ensure that their longterm survivorship concerns are heard and managed from the time of diagnosis and onwards.

\section{References}

1. SEER Stat Fact Sheets: Female Breast Cancer. Available at: http://seer. cancer.gov/statfacts/html/breast.html. Accessed October 13, 2015.

2. Oktay K, Turan V, Bedoschi G, et al. Fertility preservation success subsequent to concurrent aromatase inhibitor treatment and ovarian stimulation in women with breast cancer. J Clin Oncol 2015;33:24242429.

3. Shapira M, Raanani H, Meirow D. IVF for fertility preservation in breast cancer patients-efficacy and safety issues. J Assist Reprod Genet 2015;32:1171-1178.

4. Rosenberg SM, Newman LA, Partridge AH. Breast cancer in young women: rare disease or public health problem? JAMA Oncol 2015;1:877878.

5. Stensheim H, Cvancarova M, Moller B, Fossa SD. Pregnancy after adolescent and adult cancer: a population-based matched cohort study. Int J Cancer 2011;129:1225-1236.

6. Lee SJ, Schover LR, Partridge AH, et al. American Society of Clinical Oncology recommendations on fertility preservation in cancer patients. J Clin Oncol 2006;24:2917-2931.

7. Ruddy KJ, Gelber SI, Tamimi RM, et al. Prospective study of fertility concerns and preservation strategies in young women with breast cancer. J Clin Oncol 2014;32:1151-1156.

8. Quinn GP, Vadaparampil ST, Lee JH, et al. Physician referral for fertility preservation in oncology patients: a national study of practice behaviors. J Clin Oncol 2009;27:5952-5957.

9. Levine JM, Kelvin JF, Quinn GP, Gracia CR. Infertility in reproductive-age female cancer survivors. Cancer 2015;121:1532-1539.

10. Partridge AH, Ruddy KJ, Gelber S, et al. Ovarian reserve in women who remain premenopausal after chemotherapy for early stage breast cancer. Fertil Steril 2010;94:638-644.

11. Gracia CR, Sammel MD, Freeman E, et al. Impact of cancer therapies on ovarian reserve. Fertil Steril 2012;97:134-140.e1.

12. Abusief ME, Missmer SA, Ginsburg ES, et al. The effects of paclitaxel, dose density, and trastuzumab on treatment-related amenorrhea in premenopausal women with breast cancer. Cancer 2010;116:791-798.

13. Torino F, Barnabei A, De Vecchis L, et al. Chemotherapy-induced ovarian toxicity in patients affected by endocrine-responsive early breast cancer. Crit Rev Oncol Hematol 2014;89:27-42.

14. Bines J, Oleske DM, Cobleigh MA. Ovarian function in premenopausal women treated with adjuvant chemotherapy for breast cancer. J Clin Oncol 1996;14:1718-1729.

15. Poorvu PD, Gelber SI, Rosenberg SM, et al. Treatment-related amenorrhea among young women one year following diagnosis of early-stage breast cancer [abstract]. J Clin Oncol 2015;33(Suppl):Abstract 9523.

16. Petrek JA, Naughton MJ, Case LD, et al. Incidence, time course, and determinants of menstrual bleeding after breast cancer treatment: a prospective study. J Clin Oncol 2006;24:1045-1051.

17. Tutt A, Ellis P, Kilburn L, et al. TNT: a randomized phase III trial of carboplatin (C) compared with docetaxel (D) for patients with metastatic or recurrent locally advanced triple negative or BRCA1/2 breast cancer [abstract]. Cancer Res 2015;75:Abstract S3-01.
18. Ruddy KJ, Guo H, Barry W, et al. Chemotherapy-related amenorrhea after adjuvant paclitaxel-trastuzumab (APT trial). Breast Cancer Res Treat 2015;151:589-596.

19. Goodwin PJ, Ennis M, Pritchard KI, et al. Risk of menopause during the first year after breast cancer diagnosis. J Clin Oncol 1999;17:2365-2370.

20. Del Mastro L, Boni L, Michelotti A, et al. Effect of the gonadotropinreleasing hormone analogue triptorelin on the occurrence of chemotherapyinduced early menopause in premenopausal women with breast cancer: a randomized trial. JAMA 2011;306:269-276.

21. Su HC, Haunschild C, Chung K, et al. Prechemotherapy antimullerian hormone, age, and body size predict timing of return of ovarian function in young breast cancer patients. Cancer 2014;120:3691-3698.

22. Anderson RA, Rosendahl M, Kelsey TW, Cameron DA. Pretreatment anti-Mullerian hormone predicts for loss of ovarian function after chemotherapy for early breast cancer. Eur J Cancer 2013;49:3404-3411.

23. Dillon KE, Sammel MD, Prewitt M, et al. Pretreatment antimullerian hormone levels determine rate of posttherapy ovarian reserve recovery: acute changes in ovarian reserve during and after chemotherapy. Fertil Steril 2013;99:477-483.

24. Loren AW, Mangu PB, Beck LN, et al. Fertility preservation for patients with cancer: American Society of Clinical Oncology clinical practice guideline update. J Clin Oncol 2013;31:2500-2510.

25. von Wolff M, Thaler CJ, Frambach $T$, et al. Ovarian stimulation to cryopreserve fertilized oocytes in cancer patients can be started in the luteal phase. Fertil Steril 2009;92:1360-1365.

26. Oktay K, Buyuk E, Libertella N, et al. Fertility preservation in breast cancer patients: a prospective controlled comparison of ovarian stimulation with tamoxifen and letrozole for embryo cryopreservation. J Clin Oncol 2005;23:4347-4353.

27. Jeruss JS, Woodruff TK. Preservation of fertility in patients with cancer. N Engl J Med 2009;360:902-911.

28. Oktay K, Buyuk E, Davis O, et al Fertility preservation in breast cancer patients: IVF and embryo cryopreservation after ovarian stimulation with tamoxifen. Hum Reprod 2003;18:90-95.

29. Azim AA, Costantini-Ferrando M, Oktay K. Safety of fertility preservation by ovarian stimulation with letrozole and gonadotropins in patients with breast cancer: a prospective controlled study. J Clin Oncol 2008;26:26302635.

30. Meirow D, Levron J, Eldar-Geva T, et al. Pregnancy after transplantation of cryopreserved ovarian tissue in a patient with ovarian failure after chemotherapy. N Engl J Med 2005;353:318-321.

31. Salama M, Woodruff TK. New advances in ovarian autotransplantation to restore fertility in cancer patients. Cancer Metastasis Rev 2015;34:807822.

32. Prasath EB, Chan ML, Wong WH, et al. First pregnancy and live birth resulting from cryopreserved embryos obtained from in vitro matured oocytes after oophorectomy in an ovarian cancer patient. Hum Reprod 2014;29:276-278.

33. Moore HC, Unger JM, Phillips KA, et al. Goserelin for ovarian protection during breast-cancer adjuvant chemotherapy. N Engl J Med 2015;372:923 932.

34. Gerber B, von Minckwitz G, Stehle H, et al. Effect of luteinizing hormonereleasing hormone agonist on ovarian function after modern adjuvant breast cancer chemotherapy: the GBG 37 ZORO study. J Clin Oncol 2011;29:2334-2341.

35. Turner NH, Partridge A, Sanna G, et al. Utility of gonadotropin-releasing hormone agonists for fertility preservation in young breast cancer patients: the benefit remains uncertain. Ann Oncol 2013;24:2224-2235.

36. Vitek WS, Shayne M, Hoeger K, et al. Gonadotropin-releasing hormone agonists for the preservation of ovarian function among women with breast cancer who did not use tamoxifen after chemotherapy: a systematic review and meta-analysis. Fertil Steril 2014;102:808-815.e1.

37. Elgindy E, Sibai H, Abdelghani A, Mostafa M. Protecting ovaries during chemotherapy through gonad suppression: a systematic review and metaanalysis. Obstet Gynecol 2015;126:187-195.

38. Del Mastro L, Ceppi M, Poggio F, et al. Gonadotropin-releasing hormone analogues for the prevention of chemotherapy-induced premature ovarian failure in cancer women: systematic review and meta-analysis of randomized trials. Cancer Treat Rev 2014;40:675-683.

39. Albain KS, Barlow WE, Ravdin PM, et al. Adjuvant chemotherapy and timing of tamoxifen in postmenopausal patients with endocrineresponsive, node-positive breast cancer: a phase 3, open-label, randomised controlled trial. Lancet 2009;374:2055-2063. 
Fertility in Breast Cancer

40. Pagani O, Regan MM, Walley BA, et al. Adjuvant exemestane with ovarian suppression in premenopausal breast cancer. $\mathrm{N}$ Engl J Med 2014;371:107-118.

41. Francis PA, Regan MM, Fleming GF. Adjuvant ovarian suppression in premenopausal breast cancer. N Engl J Med 2015;372:1673.

42. Baysal O, Bastings $\mathrm{L}$, Beerendonk CC, et al. Decision-making in female fertility preservation is balancing the expected burden of fertility preservation treatment and the wish to conceive. Hum Reprod 2015;30:1625-1634

43. Kim J, Oktay K, Gracia C, et al. Which patients pursue fertility preservation treatments? A multicenter analysis of the predictors of fertility preservation in women with breast cancer. Fertil Steril 2012;97:671-676.

44. Shnorhavorian M, Harlan LC, Smith AW, et al. Fertility preservation knowledge, counseling, and actions among adolescent and young adult patients with cancer: a population-based study. Cancer 2015;121:3499_ 3506.

45. Azim HA Jr, Santoro L, Pavlidis N, et al. Safety of pregnancy following breast cancer diagnosis: a meta-analysis of 14 studies. Eur J Cancer 2011:47:74-83.
46. Kroman N, Jensen MB, Wohlfahrt J, et al. Pregnancy after treatment of breast cancer--a population-based study on behalf of Danish Breast Cancer Cooperative Group. Acta Oncol 2008;47:545-549.

47. Sankila R, Heinavaara S, Hakulinen T. Survival of breast cancer patients after subsequent term pregnancy: "healthy mother effect". Am J Obstet Gynecol 1994;170:818-823.

48. Azim HA Jr, Kroman N, Paesmans M, et al. Prognostic impact of pregnancy after breast cancer according to estrogen receptor status: a multicenter retrospective study. J Clin Oncol 2013;31:73-79.

49. Goldrat O, Kroman N, Peccatori FA, et al. Pregnancy following breast cancer using assisted reproduction and its effect on long-term outcome. Eur J Cancer 2015;51:1490-1496.

50. Burstein HJ, Winer EP. Primary care for survivors of breast cancer. N Engl J Med 2000;343:1086-1094.

51. Parulekar WR, Day AG, Ottaway JA, et al. Incidence and prognostic impact of amenorrhea during adjuvant therapy in high-risk premenopausal breast cancer: analysis of a National Cancer Institute of Canada Clinical Trials Group Study-NCIC CTG MA.5. J Clin Oncol 2005;23:60026008

\section{Instructions for Completion}

To participate in this journal CE activity: 1) review the learning objectives and author disclosures; 2 ) study the education content; 3) take the posttest with a $66 \%$ minimum passing score and complete the evaluation at http://education.nccn.org/ node/78105; and 4) view/print certificate. After reading the article, you should be able to answer the following multiple- choice questions. Credit cannot be obtained for tests completed on paper. You must be a registered user on NCCN.org. If you are not registered on NCCN.org, click on "New Member? Sign up here" link on the left hand side of the Web site to register. Only one answer is correct for each question. Once you successfully answer all posttest questions you will be able to view and/or print your certificate. Software requirements: Internet

\section{Posttest Questions}

1. True or False: Data in the post-chemotherapy population demonstrate that ovarian reserve may be diminished despite the resumption of regular menses, thus, menstruation does not necessarily connote fertility.

2. Considering available data, the best established fertility preservation strategy is:

a. Mature oocyte cryopreservation

b. Embryo cryopreservation

c. Ovarian tissue cryopreservation for reimplantation

d. Natural cycle in vitro fertilization

e. Administration of GnRH agonist concurrent with chemotherapy
3. Which of the following is a barrier to fertility preservation use for women of child-bearing age?

a. Lack of patient awareness due to inadequate discussion of treatment-related fertility risks

b. Patient perceived burden of the

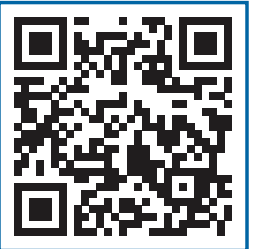
process

c. Cost

d. Anxiety about treatment delay/fear about the safety of pregnancies

e. All of the above 